Correspondence Author: Kulwinder Kaur-Bola

Affiliation: University of Bedfordshire

Address: Institute for Health Research

University of Bedfordshire

Putteridge Bury

Hitchin Road

Luton, Bedfordshire, LU2 8LE

Tel: 07966349022

E-mail: kbola@kkbkc.co.uk \& kulwinder@ntlworld.com

Author: Gurch Randhawa, Professor of Diversity in Public Health

Director, Institute for Health Research

Affiliation: University of Bedfordshire

Address: Institute for Health Research

University of Bedfordshire

Putteridge Bury

Hitchin Road,

Luton, Bedfordshire, LU2 8LE

Tel: 01582743797 or 07718517196

E-mail: gurch.randhawa@beds.ac.uk

Full title of the article: Role of Islamic Religious \& Cultural Beliefs Regarding Intellectual Impairment \& Service Use: A South Asian Parental Perspective

Short title of the article: Role of Islamic Religious \& Cultural Beliefs Regarding Intellectual Impairment \& Service Use

Word count: 7,047

Character counts including spaces: 45,525 


\section{Bionote(s):}

Kulwinder has an MSc (commendation) in Research and Evaluation. Her research focus covers health-communication/education of disadvantage adults/children, and the impact of religion/culture on accessing/accepting services among diverse communities. Kulwinder worked with Professor Randhawa on DH \& NHSBT, funded projects, exploring multi-ethnic/multi-faith perspective towards organ donation. She now freelances, undertaking projects for national children's charities, and health/social care departments.

Her e-mail address is: kbola@kkbkc.co.uk 
Gurch is a Professor of Diversity in Public Health and Director of the Institute for Health Research at the University of Bedfordshire. His research is focused on the development of patient-centred care pathways in diabetes/kidney disease/transplantation, and end-of-life care amongst diverse communities. He has received grants from organisations such as the DH, NIHR, Kidney Research UK, Big Lottery Fund, NHS BT and the King's Fund.

His e-mail address is: Gurch.Randhawa@beds.ac.uk 


\title{
Role of Islamic Religious and Cultural Beliefs Regarding Intellectual Impairment and Service Use: A South Asian Parental Perspective
}

\begin{abstract}
Empirical research has shown that some south Asian families from Muslim backgrounds may use fewer additional support services for their severely impaired children compared to other non-Muslim families. Often this has been attributed to socio-economic factors and stereotypical views such as the family's faith prohibits the use of specific services'. This paper focuses on clarifying what Islam purports to say about impairment; and considers how cultural influences may inadvertently influence some south Asian parent's decisions to use services for their severely impaired children. This work touches on improving professional- parent/patient communication by enhancing better understanding of Islam on impairment, and supporting nonMuslim professionals to appreciate the differences between Islamic religion and general south Asian cultural beliefs regarding disability. In total 14 parents from ten Pakistani and Bangladeshi families took part in semistructured open-ended interviews. Grounded theory was used to analyse the data. The emerging theory revealed most first generation Muslim families from rural villages were unable to distinguish between Islamic religious and cultural beliefs on impairment, and risked missing-out on essential services due to poor professional- parent/patient communication.
\end{abstract}

Keywords: Islamic-beliefs, Intellectual-impairment, Pakistani, Bangladeshi, Poor-communication, Service-use 


\section{Introduction}

In recent years much has been written about the inequalities experienced by some minority ethnic groups accessing services compared to other ethnic groups in the UK. A Government report, cited Muslims living in the UK as being at significant disadvantage compared to other south Asian religious groups such as Hindus, (Equalities Bill 2010: 9). Empirical evidence has also shown that Pakistani and Bangladesh families with severely physical and intellectually impaired children often experience inter-locking aspects of disadvantage resulting in stigmatisation, marginalization and discrimination (Ahmad 2000a). Furthermore when Pakistani and Bangladesh families where compared to similar British white families with severely impaired children, they were found to be much worse off (Beresford 1995; Chamba et al. 1999). In 2002, Fazil, Q. et al. reported that low socio-economic status is known to impact on this cohort's ability to communicate with professionals, and this in turn can impact on Pakistani and Bangladesh families' ability to access services for their impaired children (Author 2009).

While there is a growing body of research in general medicine and the primary care sector, which emphasises a shift in traditional thinking about professional -parent/patient communication in healthcare (Wasserman \& Inui 1983; Britten et al. 2000; Maguire \& Pitceathly 2002; and Burkitt Wright 2004), to one of parent/patient - professional collaborative communication, many difficulties still, exist. The collaborative model seems to work well if the health professionals and the parent/patients speak the same language and share a common cultural background. However difficulties in such communication 
arise when health professionals are communicating with people from different counties, with different cultures, and who speak English as an additional language. In such cases misinterpretations can occur. Effective communication can be compromised further when religious and cultural beliefs (in this case relating to impairment) may be misunderstood by the parent/patients themselves. In such cases parent's may view their children's multiple impairments as being acts of God (Butt \& Mirza 1996), or as a punishment from god, or as a blessing from god, or as a test of their faith, (Shah 1995; Croot 2008). Such interpretations can lead to some professionals holding stereotypically negative views about Islam; views such as: 'the family's faith prohibits the use of specific services' (Author 2009).

Hypothesizing as to why some services may not be used by particular communities may mask genuine difficulties around knowledge and access. For instance, beliefs such as those mentioned by Shah 1995; Butt \& Mirza 1996; and Croot 2008, can be traced back to the parent's country of origin and the cultural acceptance of disability there. For example, disability is culturally less well accepted in the sub-continent compared to in the UK. There is an emphasis on parents in the sub-continent to meet all of their impaired children's needs alone. The concept of 'care in the community' is non-existent. Government led health professionals offer little or no advice on how to care for these children. There are no support services for families with severely impaired children to use in the villages, and no access to special education or NGOs services to offer advice and act as advocates. Therefore disability is often seen by parents as life limiting for the child and burdensome 
for them. Now compare this to the culture toward disability in the UK; where legislation is instrumental and integral in protecting and supporting the needs of disabled children to live a full and happy life as possible, where parents are supported by government funded health professionals who offer services and support, and by specialist charities that provide advice and advocacy.

Attempting to explain such differences in cultural approaches towards impairment can be difficult for south Asian parents, especially if they do not fully understand them for themselves, and do not speak any English.

Although health professionals in the UK aim to use professionally trained Muslim interpreters, when communicating with non-English speaking south Asian Muslim families, this is not always possible due to budget / training / staffing restrictions. Therefore service based interpreter's (those staff members who work within the organisation, and who speak the same language as the parents/patients), are often used to bridge the gap. In addition to using service based interpreters, if health professional had a greater appreciation of Islamic religious and cultural beliefs relating to impairment then they could greatly enhance their personal communication with this cohort. Research evidence shows that good health professional and parent/patient communication is likely to results in less anxiety and burden for patients (Greenfield and Kaplan 1985; Little et al. 2001), which can then lead on to enhanced treatment satisfaction (Stewart 1984; Brody et al. 1989; Little et al. 2001), and can generally lead to greater improvement in treatment adherence (Stewart 1984). 
This paper draws on one section of a larger study to support non-Muslim health professionals and others in the position of delivering services this cohort to gain an overview of what Islam is purport to say about impairment, and in turn, to appreciate the different Islamic religious and cultural nuances that come into play when migrants move from country of origin to county of residence. Differences, which if left unexplored and unchallenged may lead to people from this cohort to miss out on essential services for their impaired children.

At the very least the authors hope to facilitate a meaningful and thought proving discussion around what constitutes effective communication between health professional and first generation, non-English speaking migrant in relation to their knowledge and access of treatment/services. 


\section{Islam - an Overview}

In essences, Islam can be defined as a way of life that unifies metaphysical and materialistic dimensions (Izetbegovic, 1993). The word Islam means submission to Allah, the supreme and only God. Individuals who practice this submission are called Muslims (Hodge, 2005) and must follow the five pillars of Islam, which include:

1) Belief in only one God - Allah,

2) Worship (five times a day),

3) Charitable giving (Zakat),

4) Fasting during the month of Ramadan (sawm), and

5) The pilgrimage to Mecca (hajj) at least once in a lifetime.

Islam is made up of two significant parts: Sunni and Shiite. Sunnis make up the majority of Muslims with approximately 90 percent worldwide; Shiites form the remaining 10 percent and are the overwhelming majority in Iran and less so in Iraq (Eickelman, 1998). In Sunni Islam, the emphasis is on a direct relationship between the believer and God unmediated by external authority structures. Conversely, Shiite Islam has a hierarchical authority structure of legal scholars formed form a consensus of the Shiite community. These scholars have the responsibility for interpreting the Word of God for the faithful (Mottahedeh, 1985).

Sufism, the mystical expression of Islam and is found among both Sunnis and Shiites followers, although it is most common among the former of the two groups (Mottahedeh, 1985). Sufis believe that a spiritual path in Islam is 
essential in order to highlight the obscure, inner dimension of faith (Waines, 1995).

As within any faith, there are often different schools of thought. Deobandi is a term used for a revivalist movement in Sunni Islam and is practiced in India, Pakistan, Afghanistan and Bangladesh and has recently spread to the United Kingdom and South Africa (Hewer 2006). This movement uses Islamic jurisprudence rulings such as 'Fiqu' (this is an expansion of the code of conduct (shari'a) expounded in the Quran, often supplemented by tradition or sunnah - based on the practices of Prophet Muhammad and implemented by the rulings and interpretations of Islamic jurists) to provide advice and guidance to the faithful. Deobandi Islam takes a harsh stance against many practices commonly associated with Barelvi Sunni Islam such as building over tombs, leading to idol worship, celebrating Milad al-Nabi (the observance of the birthday of the Islamic prophet Muhammad), and calling on the prophets and saints (Pirs) for assistance (Riaz 2008).

Barelvi Islam in contrast to Deobandi Islam is heavily influenced by Sufism and traditional folk Islamic practices (folk Islam is an umbrella term used to collectively describe the native folk beliefs, superstitions, and practices of various cultures blended within Islam, (Cook 2009)). It is often described as the Islam of the "urban poor country people, and tribes", (Ridgeon \& Lloyd 2003), in contrast to orthodox or "High" Islam (Malešević \& Haugaard. 2007) associated with jurisprudence rulings. 
While all Muslims agree shari'a should govern all facets of conduct (Eickelman, 1998), individuals who self-identify as Muslims, may themselves hold a variety of beliefs and values depending on their culture, political realities, and issues of interpretation. For instance, culture may be for some Muslims more prominent than specific Islamic beliefs (as in Barelvi Islam), and this may substantially alter some mainstream understandings of shari'a (Tarkeshwar et al. 2003). Therefore it is important for professional to appreciate that 'the key question is not what the Koran really says, but what Muslims say the Koran says' (Roy 2004). Put differently, when engaging the Muslim community in communication it worth remembering that this group is not one homogeneous mass, but made up of many smaller communities, each with their own distinct characteristics and influences (Tarkeshwar et al. 2003).

\section{Islamic religious - perceptions on impairment}

Scholarly analysis of the Qur'an has revealed that words like disability and impairment are non-existent in the text, so a literal analysis is not possible. However references were found to an all-encompassing concept that people are born equal; and that a person born with physical or intellectual disadvantage compared to others should be viewed as 'neither a blessing nor as a curse' (Bazna \& Hatab 2005), because:

"God does not burden any human being with more than he is well able to bear" (2:286 Qur'an, cited in: Bazna et al. 2005: p 21) 
Morad \& Nasri et al. (2001), expand on the concept of 'not burdening any human', by pointing out that the Qur'an places a duty on Islamic societies to assess, assist and respect a person with mental health needs, and to give those with intellectual difficulties an equal life chance. For instance, they say:

"Caring for the disabled is the duty of every Moslem and every Islamic state or society. Empathy, Human rights protection, and holistic care for this population deserve a social and economic investment..." (Morad, M. \& Nasri, Y. et al., (2001), page 8)

Using the above explanation as our bases, it would appear that Islamic religious views towards impairment encourage understanding, acceptance, and support, implying that negative views reported by parents (e.g. Shah 1995; Butt \& Mirza 1996; and Croot 2008), appear to be cultural rather than religious in origin.

\section{Method for Data Collection}

In total 14 parents from ten Pakistani and Bangladeshi families took part in 10 semi-structured interviews. The topic guides were developed in line with good practice in research interviewing (Mason, 1996). Relevant themes for the topic guide emerged from having knowledge of disability in the South Asian community, interests and style of thinking (Fleck, 1935). The questions, formed a 'who, what, why, and how' approach, and intended to gain an understanding of the viewpoint of the person(s) in the field (Bergold \& Flick 1987). Semi-structured interviews were selected because they offer both 
consistency and flexibility while adequately covering the basic topic area with all participants, and allowing options for further questioning if needed. In addition, care was taken to match female south Asian language speakers to interviewers of the same gender, religion, cultural background and dialects spoken. This required recruiting, vetting and training capable young people to be bi-lingual interviewers who were closer in terms of socio-economic status to this cohort, to support the researcher. The bi-lingual interviewers were aged between 28-38 years old, with English proficiency age of up to 18 yrs old. Asian language proficiency was tested for during the training phase as was their interpretation skills. This enabled the study to have a greater 'insider' researcher perspective (Zinn 1979), than would have otherwise been possible. All the interviews took place at the participants' homes at their request (alternative venues were available, but not used). The interviews process lasted eight weeks (March to April 2009). Each interview lasted between 60-90 minutes, and was tape recorded, translated and then transcribed verbatim by the research team or the bi-lingual interviewers. The transcripts were verified by comparing the typed text against the tape recordings of the interview.

\section{Ethical Consideration}

The topic guide, consent form and information sheet were designed, tested and then submitted for ethical approval to the Research Ethics Committee. This study was granted ethical approval by: Hertfordshire Research Ethics Committee; the NHS Research and Development body; and the University of Bedfordshire Research and Ethics committee, in January 2009. The study 
began in February 2009. The final report was presented to sponsors (Local Authority and Local Health Trust) in September 2009.

\section{Participants}

Of the ten families taking part, four were Pakistani and six were Bangladeshi. Nine out 10 families were couples; one was a divorced-single mother. Three families were aged between 20 to 30 years old. The remaining seven were aged between 30 to 40 years old. Six out of 10 mothers were born outside of the UK compared to all ten fathers. Seven out of 10 fathers had jobs working as cooks, waiters, shop assistant, or drove a taxi. One father was selfemployed and had small grocery shop. In contrast, all of the mothers were unemployed - homemakers and were the main carers of all the couple's able and impaired children. The mothers were on the whole better educated than the fathers. With seven mothers having attained the equivalent of level 5 at Key Stage 3 or above in English and Maths (English proficiency ranging from 14-18yrs old), compared to fathers who were educated to level 4, Key Stage 2 equivalent and above (English proficiency ranging from 11-16 yrs old). Most families (seven) spoke and understood English well enough not to request the services of a bi-lingual interviewer. The remaining three families spoke no English - only a dialect of Bengali known as Sylheti. These families requested the interviews be conducted in Sylheti. Of the 10 families taking part, four practiced Deobandi Islam, and six practiced Barelvi Islam. The latter is heavily influenced by Sufism and folk Islamic beliefs. All 10 families described themselves as religious, but only four (those practicing Deobandi Islam) mentioned the five pillars of Islam. Each of the 10 families taking part had one 
person who was a first generation migrant to the UK. (Table 1, p16) below, lists the above data more clearly).

\section{Recruiting the Participants}

The families were recruited by number of professional from health, social care and education (e.g. consultant community paediatrician, lead nurses, social workers, and head teachers of children centres and special schools). The selection criterion required the parents to be from either the Pakistani or Bangladeshi community, to have one or more children aged between 0-11 years old with multiple complex severe impairments such that they would need to access to two or more specialist services from health, social care/ education. 
Table 1: Participant's demographic, educational, employment information by community

\begin{tabular}{|c|c|c|c|c|c|c|c|c|c|c|c|c|}
\hline Community & $\begin{array}{l}\text { No. } \\
\text { Families: }\end{array}$ & $\begin{array}{l}\text { No of } \\
\text { individuals } \\
\text { taking part }\end{array}$ & $\begin{array}{l}\text { No. of } \\
\text { Fathers } \\
\text { taking } \\
\text { part }\end{array}$ & $\begin{array}{l}\text { No. of } \\
\text { Mothers } \\
\text { taking part } \\
\text { (Those in } \\
\text { brackets } \\
\text { born in } \\
\text { the UK) }\end{array}$ & $\begin{array}{l}\text { School of } \\
\text { Islam followed } \\
D=\text { Deobandi } \\
B=\text { Barelvi }\end{array}$ & Married & Divorced & $\begin{array}{l}\text { No of people \& } \\
\text { Age ranges }\end{array}$ & $\begin{array}{l}\text { Mother's } \\
\text { Qualifications } \\
\text { (English } \\
\text { equivalent } \\
\text { shown ) }\end{array}$ & $\begin{array}{l}\text { Father's } \\
\text { Qualifications } \\
\text { (English } \\
\text { equivalent } \\
\text { shown) }\end{array}$ & $\begin{array}{l}\text { Mother's } \\
\text { Employed }\end{array}$ & $\begin{array}{l}\text { Father's } \\
\text { Employed }\end{array}$ \\
\hline Pakistani & 4 & 6 & 2 & $4(2)$ & $3(\mathrm{~B}) 2(\mathrm{D})$ & 4 & 0 & 4: $30-40$ yrs & $\begin{array}{l}\text { 3: mothers had } \\
\text { level } 5 \text { at KS3 in } \\
\text { English and } \\
\text { Maths } \\
\text { (English } \\
\text { proficiency - up } \\
\text { to age 14yrs) } \\
\text { 1: mother had } \\
\text { an MA from } \\
\text { Lahore } \\
\text { (English } \\
\text { proficiency - up } \\
\text { to age 14yrs) }\end{array}$ & $\begin{array}{l}\text { 3: fathers had } \\
\text { the equivalent } \\
\text { of level } 4 \text { at KS2 } \\
\text { in Maths and } \\
\text { literacy (English } \\
\text { proficiency - up } \\
\text { to age 11yrs) } \\
\text { 1: father had } \\
\text { completed the } \\
\text { first year of his } \\
\text { degree in } \\
\text { Pakistan } \\
\text { (English } \\
\text { proficiency - up } \\
\text { to age 16yrs) }\end{array}$ & 0 & 2 \\
\hline Bangladeshi & 6 & 8 & 2 & $6(2)$ & 3(B) 2(D) & 5 & 1 & $\begin{array}{l}\text { 3: } 20-30 \text { yrs } \\
\text { 3: } 30-40 \text { yrs }\end{array}$ & $\begin{array}{l}\text { 1: mother had } \\
\text { level } 5 \text { at KS3 in } \\
\text { maths and } \\
\text { English } \\
\text { (English } \\
\text { proficiency - up } \\
\text { to age 14yrs) } \\
\text { 2: mothers had } \\
\text { completed their } \\
\text { A' levels } \\
\text { (English } \\
\text { proficiency - up } \\
\text { to age 18yrs) } \\
\text { 3: mothers had } \\
\text { no formal } \\
\text { education and } \\
\text { spoke no } \\
\text { English }\end{array}$ & & 0 & 5 \\
\hline
\end{tabular}




\section{Services Used by Participants}

As part of the service awareness question on the topic guide, a list of the 40 services (as shown in the list below), covering health, social services, and education were read out (and where necessary explained) to each of the 10 families. The families were then asked: a) if they had heard of these services and b) if they had used any of the services.

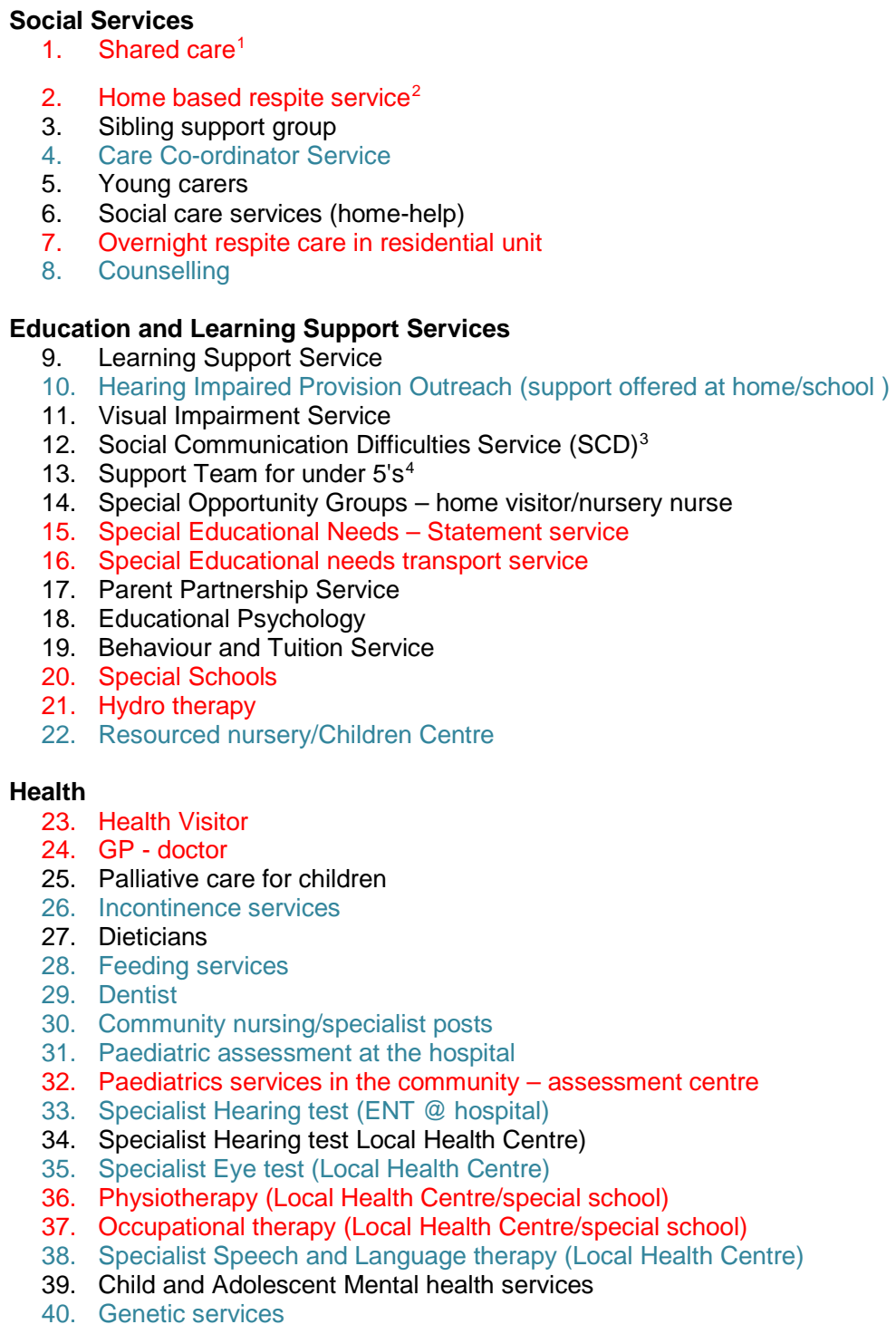

\footnotetext{
${ }^{1}$ Shared care - reregistered Foster Carers providing overnight and weekend stay for disabled children

${ }^{2}$ Home based respite service - Carers who look after the disabled child in their own home, for a few hrs, covers weekends.

${ }^{3}$ The Social Communication Difficulties (SCD) team supports the needs of children with Autistic Spectrum Disorders.

${ }^{4}$ The support team for under 5's
} 
The above lists of services was produced after brainstorming with the service providers, and are some of the services that they would expect most families with severely impaired children to be familiar with. Of the 40 services listed, 25 were known of (shown in Blue), with 14 (those shown in red) being reported as used by three families. All three families practiced Barelvi Islam, (two Bengali and one Pakistani) and had English proficiency levels equivalent to that of a 1618 year old). The remaining seven families were split into two groups: first group was made up of three non-English speakers, parents who practiced Barelvi Islam and the second group two made up of four parents who practiced Deobandi Islam, and had English proficiency levels equivalent to that of an 1114 year old. All seven of these families were able to report knowledge and use of services like the 'doctors' the 'hospital' the 'dentist' and the 'health visitor, but were unfamiliar with the other services and had not knowingly used them.

\section{Data analysis - using Grounded Theory}

After having checked the transcriptions for accuracy, the analysis was performed by reading, and re-reading through the text, asking questions of the data and writing memos, coding point of interest and then categorising these codes to form themes. Accuracy of data analysis was maintained by allowing other team members to carry out their own analysis on random copies of already analysed sections of transcript to see if they reached similar codes and categories. The codes and categories were subjected to constant comparisons so as to allow for theorizing of the participants' experiences (Glaser \& Strauss 1967; Strauss \& Corbin 1998). This cyclical approach to data collection and analysis was repeated for all 10 interviews, until data saturation was reached 
(the point at which no new codes or categories appear to be emerging). This happened after family interview number seven. In order to contextualize the emerging theory the findings were supported by a reflective log which was made after each interview. This provided a reflective stance which related to the actions, situations, and the participant's meanings during the interviews (Charmaz K 2000). The reflective log was also used to inform/update the topic guide (when appropriate), in preparation for the next family interview.

\section{Findings}

The finding revealed three main themes: confusion around Islamic cultural and religious views on impairment, fear of stigmatisation, and poor professional parent/patient communication; together they form the following theory:

"Confusing Islamic cultural and religious views on impairment may impede effective communication with health professional and result in south Asian Muslim parents missing-out on essential services for their severely impaired children."

\section{Confusion around Islamic cultural and religious views on impairment}

All 10 families taking part in this study reported one partner as being first generation settlers from the Indian sub-continent (Pakistan or Bangladesh). This is a pivotal fact as the cultural beliefs relating to impairment for these parent's would still be influenced by those of the country of origin and would not have had time to assimilate to the cultural conforms of their new home. Our findings revealed that of the 10 parents, the six who confused Islamic religion and cultural views relating to impairment were followers of Barelvi Islam. This would 
explain why one mother's parents sort religious advice once they had been made aware that their grandchild had severe learning impairments:

“... my parents were [worried in case it was bad karma/punishment from God...] they spoke to the Imam, he told them - 'those people are blessed that have disabled children like this'."

Bangladeshi Mother aged 30-40, F8

The remaining four families practiced Deobandi Islam. This group seemed to be more informed about their faith's religious views on impairment. Although there was difficulty perceived by these parents which related to the time it may take for a ruling to be made and the impact that this wait may have on taking vital decision pertaining to their children's health.

\section{Fear of stigmatisation}

The stigma associated with having an impaired child is a common phenomenon, yet it can be significantly more destructive to parent's lives in some culture compared to others. For instance, mothers in the sub-continent are often blamed for giving birth to a child with severe impairments. This is because 'impairment is perceived to be "heredity [and] mothers are fundamentally seen [to be] culpable" (Crabtree 2007). Croot 2008; and Baywater et al. 2003, both mention the concept of shame and stigmatisation in their work. These notions were prevalent in this study too. The extract below recounts the feelings of shame, despair and stigma faced by one mother after her child had been diagnosed as having major delays in physical and intellectual development leading to the diagnosis of 'global delay': 
"When [A] was diagnosed as having, 'global development delay', there were times when I would be really upset. I used to keep $[A]$ in bed all day and I used to go down and get a bottle of milk to put it in her mouth... I didn't want to go out the house and face the world... I used to be really, really upset. I used to think, 'why have I got a disabled child?' I didn't want to take $[A]$ out, because I used to feel embarrassed that somebody's going to look and say... 'Well I think she's got a disabled child... what has she done to deserve such bad kismet?'... That's how I felt."

Pakistani Mother, Practicing Barelvi Islam, aged 30-40 -F4

The mother in the above extract should have been more closely monitored by health services personnel in follow-up visits, and referred on to other services (such as family therapy, counselling and parent's groups for those with impaired children), as she clearly was not coping with her child's diagnosis. When asked if she was told about possible support services, the mother said she could not remember, suggesting that the information that was given at the time of diagnosis was not comprehended by her. This may be due to her anxiety on hearing she had a disabled child and the cultural ramification of such a verdict. Therefore it was vital that any follow-on home visits reinforced the support information and vetted her for further treatment/support. This mother also revealed that during this desperate time, she was completely alone, as her inlaws (the only family close enough to visit often) had stopped visiting regularly in case her 'bad luck' rubbed off on them. In the end it was by speaking to her 
doctor that this mother was linked into the system and began accessing the necessary services. In doing so she came to terms with her child's needs and when her in-laws saw the support this family was accessing, began visiting again - offering to baby-sit their grandchild, while the mother did her house work.

In another case, a mother coped with the stigma of having an impaired child by drawing strength from her faith in a particle way. She approached her Imam in person, taking her impaired child with her to seek religious advices and support. The Imam on providing this began conducting home visits, therefore supporting the whole family. Support of this kind has been vital for this mother who now feels less stigmatised:

“... [The] Imam sometimes drops in to the house to see my son. He is supportive. That's why I can't be depressed anymore... My parents [also] talked to the Imam and [he told them]"... [If] you take good care of [the impaired child] in this world, [then] God will do you good in the next world"

Bangladeshi Mother, Practicing Barelvi Islam, aged 30-40, F8

By visiting the impaired child at home, this Imam has provided this family with his religious seal of approval and support. His action has planted the seed of acceptance amongst the wider family and within the local community, showing that Islam views impairment is a normal part of human life. Such actions have helped this mother to re-build her fragmented relationship with the extended family and reduce her sense of isolation and feelings of stigmatisation. 
Moreover, the Imam's actions have helped to empower this mother be a source of support and advocacy for other mothers in similar situations.

\section{Poor professional- parent/patient communication}

Here the findings revealed that while the three families who had English proficiency of between 16-18 years old, reported they had good communicate with professionals, and were able to access a number of services (25 / 40); and were more inclined to ask questions, this was not always indicative of clear professional parent/patient communication. This was because on occasions some professionals had a tendency to over simplify the diagnosis (possibly to aid parental understanding of a complex conditions), but in doing this they inadvertently gave the wrong impression. In the abstract below one mother explains how she misunderstood the seriousness of her child's diagnosis because of what she was told:

“..first of all they said [B] could [have a] floppy larynx, but they [were] not $100 \%$ sure - [I was told that] usually the child is discharged after a while and it takes about 8/9 months [before] the child actually starts eating solids, [and as the child] grows [the condition] goes away... To be honest I wasn't really worried... 'Floppy larynx', I thought, that's nothing severe... But then they [were] going to send [B] to the [specialist hospital], [so] they [couldn't] discharge her... but because she was quite stable, than more severe children, she kept getting [pushed] down the waiting list. I got so frustrated because [I'd] just given birth to a child, [and] I [don't] know what was wrong with her, [no one] would help me to understood. I 
think that's what annoyed me the most - I [just wanted] a date to [go]. I felt they [staff] knew what was wrong with her [but no one told me or how serious it was], I had to wait 4 weeks! They should have been more understanding and thought how all this was affecting me..."

Bangladeshi Mother aged 20-30, F3

Unclear and overcautious professional parent/patient communications can leave parents perplexed and suspicious of the medical staff. In the above extract the mother is convinced that the medical professionals are keeping key facts about her child's health from her. She bases this belief on professionals giving her mixed messages such as - 'most likely' has a '...floppy lynx', but no explanation is given as to what this condition is or how serious it may be. She is then further confused as she expects to take her baby home but is told she cannot as her baby has to be seen by specialist, but information about how long she may have to wait is not shared. Furthermore, the mother is not prepared in advance for other alterative diagnosis. Eventually when she sees the specialist, she is dealt a crippling blow as her child is diagnosed as having an extremely rare lifelong condition which will require regular medical care. While it not always be possible to give a clear/accurate diagnosis it is imperative that professionals are clear and explain as far as possible the best and worst case outcomes of any diagnosis. The mother's testimony was emotionally charged and although this happened some years ago, recalling it evolved a fresh sense of outrage at the way she was treated at that time. 
In contrast, if non-English speaking Bengali families are considered, then the findings show that this group found professional parent/patient communications difficult and often very stressful because in their opinion the professionals did understand their needs. This group comment on how not being able to speak English coupled with not knowing who to ask for advice and help had directly impacted on the level of support they received for their children. They base this belief on comparing the levels of support provided to them when their children were babies (which was good), against a period of about 18 months when the support seemed to faded away - only to be picked-up again once the children started formal education (such as children centre or special school). The period of no support left the families perplexed and full of despair. Speculations as what may have caused services to fade are not clear, but point to service handover and some requirement on the families to register their needs seem plausible reasons. However the fade in services may have been avoided altogether if professional parent/patient communication had explained such processes in advance.

\section{Discussion}

Appreciating Islamic religious view on disability is clear (people with impairments should have the same life changes as everyone else), but in order to understand what is permissible within Islamic culture is less clear. The latter will depends on cultural interpretations of disability, which in turn are informed by the individual's level of education, political stance and environmental influences. In this study all first generation Barelvi practicing Muslim migrants, from the subcontinent, found it difficult to distinguish between religious and 
cultural beliefs relating to impairment. However knowledge and understanding of impairment and the processes involved in accessing services helped three of the more educated parents from this group to access a greater range of services for their impaired children. While previously confusing such beliefs may have lead to the child with impairments being seen as 'a test of faith', (Shah 1995; Croot 2008), in which case accepting external support may be deemed as failing that test, educated, parents have changed the narrative from a negative to a positive, whereby the test is no longer enduring hardship, but finding ways to help the child access every opportunity in order to live a full and happy life.

Reflection on the work undertaken in this study, it would stand to reason that a Muslim family's perception of their child's impairment depends on their educational attainment and not on which school of Islamic teaching they adhered to (Deobandi or Barelwi). However, tackling culture specific stigmas relating to impairment is urgently needed, preferably supported by Barelwi Imams working with health professionals within their local communities. In addition, this work touched on how non-English speaking Muslim families can potentially be lost to services after having fallen between the gaps created by service transfers. To ensure equalities of services are maintained, health professionals are urged to develop individual service plans for vulnerable families whom speak little or no English, to ensure service transfer occur seamlessly. Furthermore, health professional should remain mindful of the importance of maintaining, clear and accurate lines of professional parent/patient communication at all times, and avoids the urges to over simplify 
complex undiagnosed conditions. They should help vulnerable families be aware of their rights and provide support for those wishing to make a complaint.

To assist non-Muslim health professionals to communicate with greater confidence with families from this cohort, the following steps are recommended:

a) Familiarise yourself with the two schools of Islamic teaching (Deobandi and Barelvi);

b) Identify which group your parent/patients belong to;

c) Use your learning to facilitate communication.

\section{Conclusion}

Having a common understanding and respect for differences represent an inclusive society. Equality legislation in the UK has over the years contributed towards changing cultural perception towards impairment and this has led to greater public awareness and acceptance of disabilities. Education authorities have been pivotal in promoting a new inclusive ethos of valuing diversity in all their schools. Nevertheless in a multi-ethnic and multi-faith society such as the UK, enhancing cultural awareness relating to impairment remains an ongoing challenge. This paper considers the role of Islamic religious and cultural beliefs regarding intellectual impairment and service use among south Asian Muslim parents with severely impaired children. It concludes that while Islamic religious views towards impairment appear to be constant, cultural influences waver 
between the negative and positive, and depends on the parent's educational attainment and not different Islamic teachings (Deobandi or Barelwi). Those parents with higher educational attainment tended to communicated better with professionals and accessed a wider range of services compared to those with lower attainment. 


\section{References}

Ahmad, W.I.U. (Ed) (2000a) Ethnicity, Disability and Chronic IIIness, Buckingham, Open University Press.

Bazna, M. S. \& Hatab, T. A. (2005) Disability in the Qur'an: The Islamic Alternative to Defining, viewing and Relating to Disability Journal of Religion, Disability \& Health, 9(1) pp. 5 - 27.

Beresford, B. (1995) Expert Opinions: A National Survey of Parents Caring for a Severely Disabled Child, Social Policy Research Unit, University of York: York.

Bergold, J.B. \& Flick, U. (1987) A views Approaches to the subject's perspective using qualitative research. London: DGVT publisher.

Britten, N. Stevenson, F. A. Barry, C. A. Barber, N. and Collins, P. B. (2000) Misunderstandings in prescribing decisions in general practice: Qualitative study. British Medical Journal 320: 484-489.

Brody, D. S. Miller, S. M. Lerman, C. E. Smith, D. G. and Blum, M. J. (1989) The relationship between patients' satisfaction with their physicians and perceptions about interventions they desired and received, Medical Care 27: 1027- 1035 .

Burkitt Wright, E. (2004) Doctors communicating trust, care and respect. British Medical Journal 328: 1317-1318.

Butt, J. \& Mirza, K. (1996) Social Care and Black Communities, HMSO, London.

Bywwaters, P. Ali, Z. Fazil, Q. Wallace, L.M., Singh, G. (2003) Attitudes towards disability amongst Pakistani and Bangladeshi parents of disabled children in the UK: considerations for service professionals and the disability movement, Health and Social Care in the Community, 11(6), pp. 502-509. 
Chamba, R. Ahmad, W. Hirst, M. Lawton, D. and Beresford, B. (1999) Minority ethnic families caring for a severely disabled child, Joseph Rowntree Foundation Publication.

Charmaz, K. (2000) Grounded theory: Objectivists and constructivist methods, In N. K. Denzin \& Y. S. Lincoln, Handbook of Qualitative Research (2 ${ }^{\text {nd }} \mathrm{ed} . \mathrm{pp}$ 509-535), Thousand Oaks, CA: Sage.

Cook, C. (2009) Spirituality and Psychiatry. RCPsych Publications. p. 242. ISBN 978-1904671718.

Crabtree, S, A. (2007) Family responses to the social inclusion of children with developmental disabilities in the United Arab Emirates, Disability \& Society, 22(1), pp. $49-62$.

Croot, E. J. (2008) Perceptions of the causes of childhood disability among Pakistani families living in the UK, Health \& Social Care in the Community, 16(6), pp. $606-613$.

Eickelman, D. F. (1998) The Middle East and Central Asia (3rd ed.) Upper Saddle River, NJ: Prentice Hall.

Fazil, Q. Bywater, P. Ali, Z. Wallace, L. M. Singh, G. (2002). Disadvantage and Discrimination Compounded: the experience of Pakistani and Bangladeshi parents of disabled children in the UK, Disability \& Society, 17(3), pp. 237-253.

Fleck , L. (1935) Genesis and Development of a Scientific Fact, eds T.J. Trenn and RK Merton 1979. Chicago: University of Chicago Press.

Glaser, B.G. \& Strauss, A. L. (1967) The Discovery of Grounded Theory, New York, Aldine. 
Greenfield, S. and Kaplan, S. J. E. W. (1985) Expanding patient involvement in care. Effects on patient outcomes, Annual International Medicine 102: 520-528.

Hewer. C.T.R. (2006) Understanding Islam the first 10 Steps, London, SCM. ISBN 9780334040323

Hodge, D.R. (2005) Social Work and the House of Islam: Orienting Practitioners to the Beliefs and Values of Muslims in the United States Social Work, 50 (2): 162-173.

Izetbegovic, A. A. (1993) Islam between East and West (3rd ed.), Plainfield, IN: American Trust Publications.

Author. (2009). Exploring the Needs of Children with Multiple, Complex Disability and Learning Difficulties from the Pakistani and Bangladeshi Communities, Research Report for LA and PCT

Little, P. Everitt, H. Williamson, I. Warner, G. Moore, M. Gould, C. Ferrier, K. and Payne, S. (2001) Observational study of patient centeredness and positive approach on outcomes of general practice consultations, British Journal of Psychiatry, 323: 908-911.

Maguire, P. Pitceathly, C. (2002) Key communication skills and how to acquire them. British Medical Journal 325: 697-700.

Mason, J. (1996) Qualitative Researching, London: Sage.

Malešević, S. and Haugaard, M. (2007) Ernest Gellner and Contemporary Social Thought Cambridge University Press. p.189.

ISBN 978-0521709415.

Morad, M. Nasri, Y. \& Merrick, J. (2001) Islam and the Person with Intellectual Disability, Journal of Religion, Disability and Health, 5(2\&3), pp. 65-71. 
Mottahedeh, R.P. (1985) The mantle of the Prophet: Religion and politics in Iran, Simon and Schustwe, NJ.

ISBN 0671551973

Ridgeon, Lloyd (2003). Major World Religions: From Their Origins to the Present. Routledge. p. 280.

ISBN 978-0415297967

Riaz. A. (2008) Faithful Education: Madrassahs in South Asia, NJ, USA:

Rutgers University Press.

ISBN 978-0-8135-4345-1

Roy, O. (2004) Globalized Islam: The Search for A New Ummah, Columbia University Press, NY.

ISBN 0-231-13498-3

Shah, R. (1995) The Silent Minority - Children with Disabilities in Asian Families, National Children's Bureau, London.

Stewart, M. (1984) What is a successful doctor-patient interview? A study of interaction and outcomes, Social Science and Medicine 19 (2): 167-175.

Strauss, A. \& Corbin, J. (1998) 'Grounded Theory Methodology: An Overview', In N. K. Denzin \& Y.S. Lincoln (eds.) Strategies of Qualitative Inquiry, pp 15883, London, Sage.

Tarkeshwar, N. Stanton, J. Pargment, K.I. (2003) Religion: An Overlooked Dimension in Cross-Cultural Psychology Journal of Cross-Cultural Psychology, $34 ; 377$

Wasserman, R. C. and Inui, T. S. (1983) Systematic analysis of clinician-patient interactions: A critique of recent approaches with suggestions for future research Medical Care XXI: 279. 
Waines, D. (1995) An Introduction to Islam, Cambridge, England, Cambridge University Press.

Zinn, M.B. (1979) Field Research in Minority Communities: Ethical, Methodological and Political Observations by an Insider, Social Problems, Vol. 27, No. 2, 209-219. 